\title{
Environmental factors determining wing form in the lygaeid bug, Dimorphopterus japonicus (Heteroptera: Lygaeidae)
}

\author{
Rikiya Sasaki, Fusao Nakasuji and Kenji Fujisaki ${ }^{1}$ \\ Faculty of Agriculture, Okayama University, Okayama 700-8530, Japan \\ ${ }^{1}$ Graduate School of Agriculture, Kyoto University, Kyoto 606-8502, Japan \\ (Received 14 December 2001; Accepted 22 February 2002)
}

\begin{abstract}
Dimorphopterus japonicus, a lygaeid bug which mainly feeds on the eulalia, Miscanthus sinensis, shows a marked wing dimorphism of brachyptery and macroptery. Our preliminary experiments suggested that temperature, photoperiod and density during the nymphal stage are important for the determination of wing form in D. japonicus. The purpose of this study was to elucidate, by more detailed experimentation, the relationships between each environmental factor and the incidence of macroptery. Environmental factors such as high temperature, long photoperiod, and crowding during the nymphal stage stimulated the production of macropters in D. japonicus. Moreover, the incidence of macroptery increased with increase in temperature, photoperiod and density. Results that no macropters appeared at a density of 1,2 and 5 individuals per container, might indicate that body contact among bugs is necessary for macropter development and the fact that the incidence of macroptery increased, depending on crowding, is suggestive of a strategy for escape from deteriorating habitats. Moreover, both conspecific crowding and seasonal factors, such as temperature and photoperiod, were important in the determination of wing form. The strong effect of seasonal factors such as temperature and photoperiod on wing-form determination implies that wing dimorphism has evolved as a component of seasonal adaptation.
\end{abstract}

Key words: Dimorphopterus japonicus, wing dimorphism, temperature, photoperiod, density

\section{INTRODUCTION}

Many insects have secondarily evolved flightlessness or have become polymorphic for the ability to disperse by flight (Roff, 1990; Zera and Denno, 1997). The most commonly studied type of dispersal polymorphism is a wing polymorphism that involves discontinuous variation in the length of the wings (Harrison, 1980; Roff, 1986; Zera and Denno, 1997). These studies have made important contributions to our understanding of dispersal per se in addition to advancing our understanding of population dynamics and species interactions, life history evolution, and the physiological basis of adaptation. Studies of wing polymorphism have also played a significant role in the development of ideas concerning the interaction between dispersal and other life history traits such as fecundity, age at first reproduction, and diapause (Zera and Denno, 1997).

The distribution of the lygaeid bug, Dimorphopterus japonicus, includes the Honshu, Shikoku and Kyushu regions and the Tishima Islands in Japan, the Russian Far East and China (Hirashima,
1989). The nymphs and adults suck the sap of the eulalia, Miscanthus sinensis, a perennial grass widely distributed in Japan. They are found between the plant spindle and overlapping young leaves or inside the sheaths of older, less tightly wrapped leaves. This bug is wing-dimorphic ( $\mathrm{Fu}-$ jita, 1977; Sasaki et al., 2002). Adults have either fully developed wings (macropter) or have reduced wings (brachypter).

Wing morph can result most commonly from a combination of both genetic and environmental variation (Harrison, 1980; Zera and Denno, 1997). Environmental factors, such as temperature, photoperiod and crowding have been observed to influence wing form. Our preliminary experiments suggested that temperature, photoperiod and density in the nymphal stage are important for the determination of wing form in D. japonicus (Sasaki et al., 2002). The purpose of this study is to clarify relationships between each of these environmental factors and the incidence of macroptery by more detailed experimentation. 


\section{MATERIALS AND METHODS}

Incidence of macroptery at various rearing temperatures. Newly emerged individuals of the 1 st generation of $D$. japonicus were collected from a $M$. sinensis patch in Okayama, western Honshu Island, Japan in August 1999. They were brought to the laboratory and reared in groups in $900-\mathrm{ml}$ transparent plastic containers $(9.4-\mathrm{cm}$ in diameter, $16-\mathrm{cm}$ in height) under $16 \mathrm{~L} 8 \mathrm{D}$ and $25^{\circ} \mathrm{C}$ conditions and were provided with several chopped stalks and leaves (15-cm long) of M. sinensis as food and substrate for oviposition. The eggs laid by these adults were used for this experiment. Firstinstar nymphs were reared at 20.0, 22.5, 25.0, 27.5 and $30.0^{\circ} \mathrm{C}$, under $16 \mathrm{~L} 8 \mathrm{D}$ at a density of 15 individuals per $50-\mathrm{ml}$ glass vial $(4.0-\mathrm{cm}$ in diameter, $7.5-\mathrm{cm}$ in height) with a chopped stalk of $M$. sinensis (7-cm long). Five replicates were done for each temperature regime. The food and containers were replaced with new ones every 3 days. Wing form was checked after adult eclosion according to Sasaki et al. (2002). Wing form is quite defined, and discrimination is straightforward and reliable (Fig. 1).

Incidence of macroptery under various photoperiod conditions. Newly emerged individuals of the 1st generation of D. japonicus were collected from a $M$. sinensis patch at Notorohara, the north- ern district of Okayama Prefecture, on September 3, 1998. They were brought to the laboratory and reared in groups in 900-ml transparent plastic containers under $16 \mathrm{~L} 8 \mathrm{D}$ and $25^{\circ} \mathrm{C}$ conditions and were provided with several chopped stalks and leaves of $M$. sinensis as food and substrate for oviposition. The eggs laid by these adults were used for this experiment. First-instar nymphs were reared at under $12 \mathrm{~L} 12 \mathrm{D}, 13 \mathrm{~L} 11 \mathrm{D}, 13.5 \mathrm{~L} 10.5 \mathrm{D}$, 14L10D, 14.5L 9.5D and 15.5L8.5D photoperiod conditions. Rearing was conducted at $25^{\circ} \mathrm{C}$ and at a density of 15 individuals per $50-\mathrm{ml}$ glass vial with a chopped stalk of $M$. sinensis. Five replicates were done for each photoperiod regime. The food and containers were replaced with new ones every 3 days. Wing form was checked after adult eclosion.

Incidence of macroptery at various rearing densities. This experiment was carried out twice in 1998 and 1999. First, post-overwintering adults of D. japonicus were collected from a $M$. sinensis patch in Okayama on May 7, 1998. They were brought to the laboratory and reared in groups in 900-ml transparent plastic containers under 16L8D and $25^{\circ} \mathrm{C}$ conditions and were provided with several chopped stalks and leaves of $M$. sinensis as food and substrate for oviposition. The eggs laid by these adults were used for this experiment. Firstinstar nymphs were reared at densities of 1, 2, 5, 10

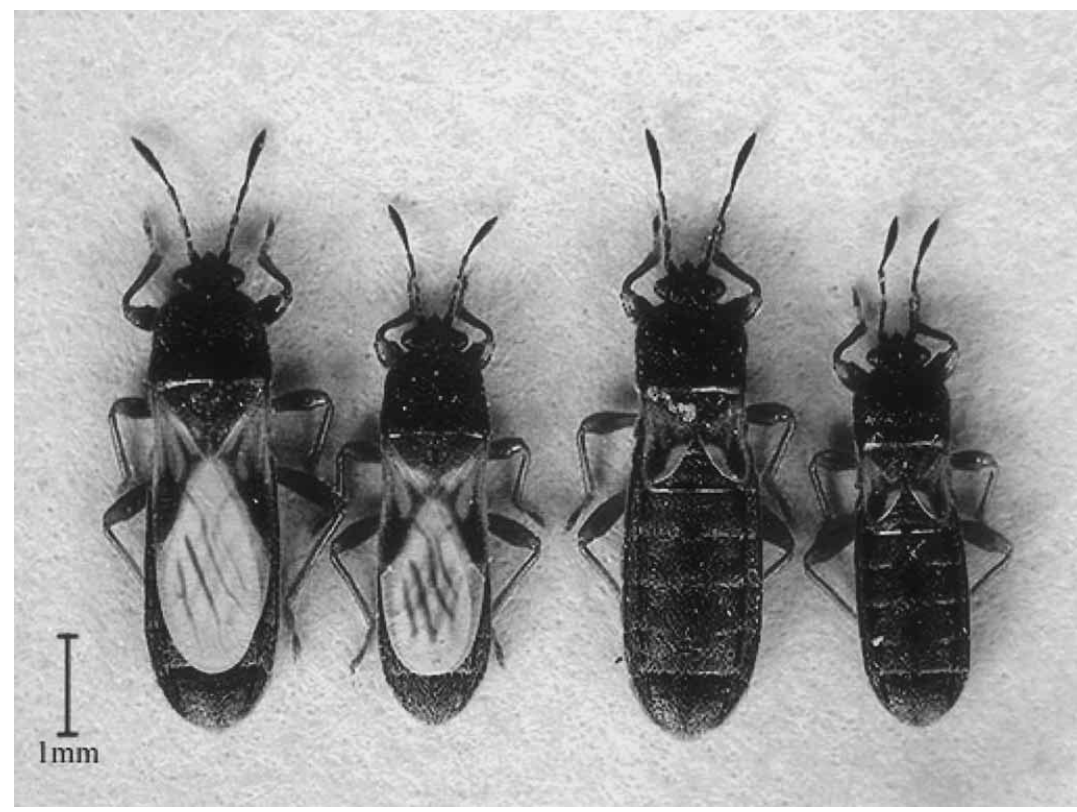

Fig. 1. Adults of D. japonicus. From the left, macropterous female, macropterous male, brachypterous female, and brachypterous male. 
and 20 individuals per $50-\mathrm{ml}$ glass vial with a chopped stalk of $M$. sinensis. Rearing conditions were $16 \mathrm{~L} 8 \mathrm{D}$ at $25^{\circ} \mathrm{C}$. The number of replications at each density was 20 ( 1 individual), 15 ( 2 individuals), 10 (5 individuals), 5 (10 individuals) and 3 (20 individuals). Second, newly emerged individuals of the 1 st generation of D. japonicus were collected from a M. sinensis patch in Okayama in August 1999. They were reared under the same conditions as in the first experiment. The eggs laid by these adults were used for this experiment. Firstinstar nymphs were reared at densities of 15,30 and 50 individuals per 50-ml glass vial. Other rearing conditions were the same as in the first experiment. The number of replications at each density was 5 (15 individuals), 3 (30 individuals) and 2 (50 individuals). The food and containers were replaced with new ones every 3 days. Wing form was checked after adult eclosion.

\section{RESULTS}

\section{Incidence of macroptery at various rearing tem- peratures}

Figure 2 shows the incidence of macroptery at various rearing temperatures. In females, macropters appeared at all temperatures examined, but no macropter males occurred at $20.0^{\circ} \mathrm{C}$. The incidence of macroptery increased with temperature in both sexes. In all regimes, the incidence of macroptery tended to be higher in females than in males and the difference at $27.5^{\circ} \mathrm{C}$ was statistically significant $(p<0.05$, Mann-Whitney $U$-test $)$.

\section{Incidence of macroptery under various pho- toperiod conditions}

Figure 3 shows the incidence of macroptery under various photoperiod conditions. Macropters appeared at photoperiod range of 13L11D to 15.5L8.5D and its incidence increased with an increase in photoperiod in both sexes. In all regimes except for $12 \mathrm{~L} 12 \mathrm{D}$, the incidence of macroptery tended to be higher in females than in males, although the differences were not statistically significant $(p>0.05$, Mann-Whitney $U$-test).

\section{Incidence of macroptery at various rearing den- sities}

Figure 4 shows the incidence of macroptery at various rearing densities. Macropters appeared at a

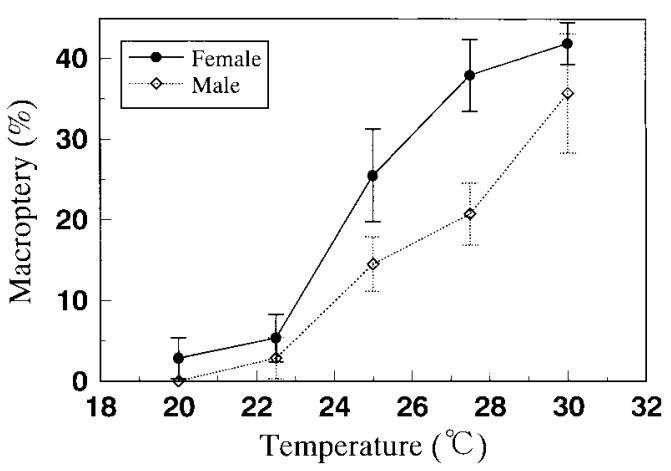

Fig. 2. Incidence of macroptery at various rearing temperatures in $D$. japonicus under $16 \mathrm{~L} 8 \mathrm{D}$ at a density of 15 individuals per container. Vertical lines show standard error.

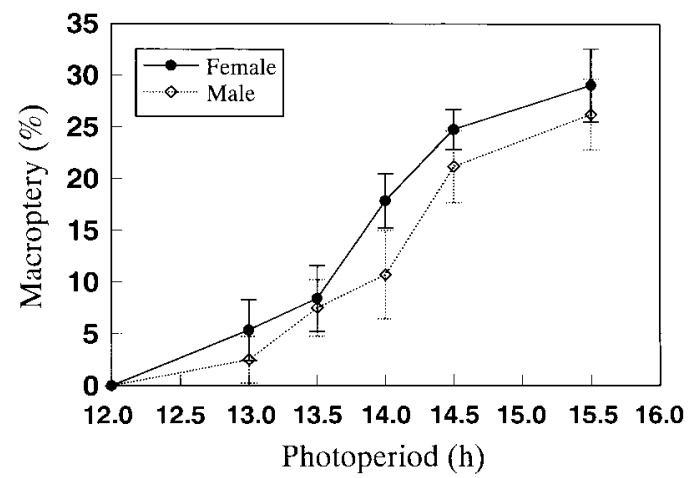

Fig. 3. Photoperiodic response in the incidence of macroptery in $D$. japonicus at $25^{\circ} \mathrm{C}$ and at a density of 15 individuals per container. Vertical lines show standard error.

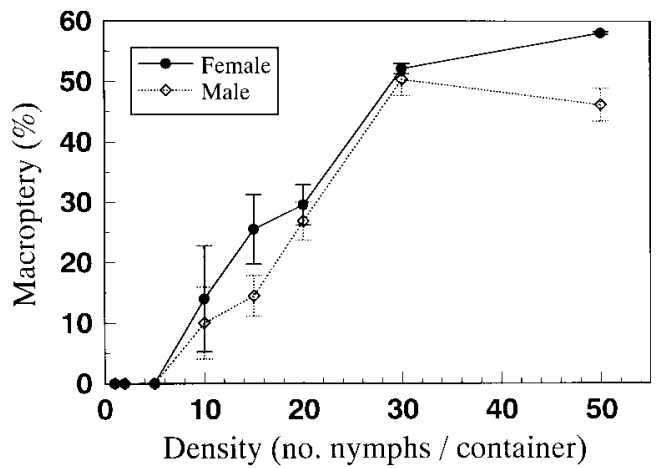

Fig. 4. Incidence of macroptery at various rearing densities in D. japonicus under $16 \mathrm{~L} 8 \mathrm{D}$ at $25^{\circ} \mathrm{C}$. Vertical lines show standard error.

density of 10 to 50 individuals in both sexes. In females, the incidence of macropters increased with rearing density. The same pattern was obtained in males except that it decreased slightly at a high density of 50 individuals. At all densities where 
macropters emerged, its incidence tended to be higher in females than in males, although the difference was not statistically significant $(p>0.05$, Mann-Whitney $U$-test).

\section{DISCUSSION}

The present results indicate that environmental factors such as high temperature, long photoperiod, and crowding during the nymphal stage favor the production of macropters in D. japonicus. Various environmental cues are known to influence wing form (Harrison, 1980; Zera and Denno, 1997). For example, in Dimorphopterus pallipes (Hirata et al., 1998) and the oriental chinch bug, Cavelerius saccharivorus (Murai, 1975; Oshiro, 1981; Fujisaki, 1986, 1989), more macropters are produced under rearing conditions of higher density, longer photoperiod, and higher temperature. However, in a pyrrhocorid bug, Pyrrhocoris sibiricus, high temperature, short day-length and moderate crowding are favorable conditions for the production of macropters (Sakashita et al., 1995). Thus, the environmental factors responsible for the production of macropters depend upon the species.

The production of macropters is density-dependent in many species and is intensified by limited or nutritionally inadequate food (Harrison, 1980; Zera and Denno, 1997). Denno and Roderick (1992) suggested that, in planthoppers, the effect of density on wing form resulted from: (1) planthopperinduced changes in plant physiology that directly influence the developmental switch determining the wing form, and (2) density-related modifications in insect behavior that alter food availability and/or tactile stimulation among individuals triggers the developmental switch. The present finding that no macropters appeared at densities of 1,2 and 5 individuals per container may indicate that frequent body contact among bugs is necessary for macropter development in D. japonicus. The fact that the incidence of macroptery increased depending on crowding suggests that $D$. japonicus employ a strategy for escape from deteriorated habitat. Perhaps, food conditions at low densities may be relatively better. Vascular sap-feeding homopterans share the most mobile component of their host plant and can compete directly for nutrients even if they are spatially separated (Moran and Whitham, 1990). This leads to a close relationship between density on the host plant and nutritional condition of the host plant. It is important to determine the effect of host plant condition on wing form.

The effect of photoperiod on wing-form determination implies that wing dimorphism has evolved as a component of seasonal adaptation. Photoperiod, an astronomical and hence particularly reliable cue, is used most commonly, typically based only on its absolute value acting through a response threshold (Danks, 1994). In C. saccharivorus populations, density increases from early summer (1st generation) to mid-summer (2nd generation) (Fujisaki, 1989). The production of macropters in response to long photoperiod and high temperature appears highly adaptive in this bug, because macropters can escape from crowded habitats and colonize more favorable ones (Fujisaki, 1985). A seasonal variation in wing dimorphism is seen in some water striders. In a water strider, Limnoporus canaliculatus, the 1st generation of summer adults are mostly short-winged or apterous and direct breeders, while the 2nd generation adults are macropterous and enter diapause (Zera et al., 1983; Zera and Tiebel, 1991). The major environmental factor controlling wing form in this species was experimentally demonstrated to be photoperiod (Zera et al., 1983). Seasonal factors, especially photoperiod, serve to determine the timing of emergence of macropters in the field. In D. japonicus, however, the life cycle, as well as seasonal changes in the proportion of macropters, are largely unknown. Field surveys on life history traits are necessary to understand the significance of the environmental control of wing form in this bug.

\section{REFERENCES}

Danks, H. V. (1994) Diversity and integration of life-cycle controls in insects. In Insect Life-Cycle Polymorphism $(\mathrm{H}$. V. Danks ed.). Kluwer Academic Publishers, Dordrecht, pp. 5-40.

Denno, R. F. and G. K. Roderick (1992) Density-related dispersal in planthoppers: effects of interspecific crowding. Ecology 73: 1323-1334.

Fujisaki, K. (1985) Ecological significance of the wing polymorphism of the oriental chinch bug, Cavelerius saccharivorus Okajima (Heteroptera: Lygaeidae). Res. Popul. Ecol. 27: 125-136.

Fujisaki, K. (1986) Genetic variation of density responses in relation to wing polymorphism in the oriental chinch bug, Cavelerius saccharivorus Okajima (Heteroptera: Lygaeidae). Res. Popul. Ecol. 28: 219-230. 
Fujisaki, K. (1989) Wing form determination and sensitivity of stages to environmental factors in the oriental chinch bug, Cavelerius saccharivorus Okajima (Heteroptera: Lygaeidae). Appl. Entomol. Zool. 24: 287-294.

Fujita, K. (1977) Wing form composition in the field population of the two species of lygaeid bugs, Dimorphopterus pallipes and D. japonicus, and its relation to environmental conditions. Jpn. J. Ecol. 27: 263-267 (in Japanese with English summary).

Harrison, R. G. (1980) Dispersal polymorphisms in insects. Annu. Rev. Ecol. Syst. 11: 95-118.

Hirashima, Y. (ed.) (1989) A Check List of Japanese Insects, Vol. 1. Kyushu Univ. Entomol. Lab., Fukuoka. 174 pp. (in Japanese).

Hirata, T., F. Nakasuji and K. Fujisaki (1998) Factors determining the wing form of a lygaeid bug, Dimorphopterus pallipes Distant (Heteroptera, Lygaeidae). Chugoku Kontyu 12: 37-41 (in Japanese with English summary).

Moran, N. A. and T. G. Whitham (1990) Interspecific competition between root-feeding and leaf-galling aphids mediated by host plant resistance. Ecology 71: 1050-1058.

Murai, M. (1975) Population studies of Cavelerius saccharivorus Okajima (Heteroptera: Lygaeidae): A few findings on population interchange. Res. Popul. Ecol. 17: 5163.

Oshiro, Y. (1981) Studies on the population dynamics of the oriental chinch bug, Cavelerius saccharivorus (Okajima) (Heteroptera, Lygaeidae) in the sugarcane field. Part 2.
Effects of temperature, day length and population density on the appearance of the macropterous adult. Konty $\hat{u} 49$ : 385-389 (in Japanese with English summary).

Roff, D. A. (1986) The evolution of wing dimorphism in insects. Evolution 40: 1009-1020.

Roff, D. A. (1990) The evolution of flightlessness in insects. Ecol. Monogr. 60: 389-421.

Sakashita, T., K. Fujisaki and F. Nakasuji (1995) Environmental factors affecting wing length variation of a stink bug, Pyrrhocoris sibiricus (Heteroptera: Pyrrhocoridae). Appl. Entomol. Zool. 30: 303-308.

Sasaki, R., F. Nakasuji and K. Fujisaki (2002) Wing dimorphism and environmental factors influencing the wing form determination in the lygaeid bug, Dimorphopterus japonicus (Heteroptera, Lygaeidae). Chugoku Kontyu 15: $47-52$.

Zera, A. J. and R. F. Denno (1997) Physiology and ecology of dispersal polymorphism in insects. Annu. Rev. Entomol. 42: 207-231.

Zera, A. J., D. J. Innes and M. E. Saks (1983) Genetic and environmental determinants of wing polymorphism in the waterstrider, Limnoporus canaliculatus. Evolution 37: 513-522.

Zera, A. J. and K. C. Tiebel (1991) Photoperiodic induction of wing morphs in the waterstrider, Limnoporus canaliculatus (Gerridae: Hemiptera). Ann. Entomol. Soc. Am. 85: 508-516. 